\title{
PROP1 gene mutations in a 36-year-old female presenting with psychosis
}

\author{
Durgesh Prasad Chaudhary', Tshristi Rijal', Kunal Kishor Jha² and Harpreet Saluja ${ }^{3}$ \\ 1BP Koirala Institute of Health Sciences, Dharan, Nepal, ${ }^{2}$ Critical Care Medicine, Geisinger Medical \\ Center, Danville, Pennsylvania, USA, and ${ }^{3}$ RCSI, Busaiteen, Bahrain
}

Correspondence should be addressed to D P Chaudhary Email durgeshchaudhary11@gmail. com

\section{Summary}

Combined pituitary hormonal deficiency (CPHD) is a rare disease that results from mutations in genes coding for transcription factors that regulate the differentiation of pituitary cells. PROP1 gene mutations are one of the etiological diagnoses of congenital panhypopituitarism, however symptoms vary depending on phenotypic expression. We present a case of psychosis in a 36-year-old female with congenital panhypopituitarism who presented with paranoia, flat affect and ideas of reference without a delirious mental state, which resolved with hormone replacement and antipsychotics. Further evaluation revealed that she had a homozygous mutation of PROP1 gene. In summary, compliance with hormonal therapy for patients with hypopituitarism appears to be effective for the prevention and treatment of acute psychosis symptoms.

\section{Learning points:}

- Patients with PROP1 gene mutation may present with psychosis with no impairment in orientation and memory.

- There is currently inadequate literature on this topic, and further study on the possible mechanisms of psychosis as a result of endocrine disturbance is required.

- Compliance with hormonal therapy for patients with hypopituitarism appears to be effective for prevention and treatment of acute psychosis symptoms.

\section{Background}

Acute psychosis and mood symptoms are uncommon in hypopituitarism but have been reported in patients following a traumatic brain injury, those with Sheehan's syndrome or after glucocorticoid therapy $(1,2,3)$. Neuropsychiatric manifestations have also been reported in cases with panhypopituitarism. Diagnosis is difficult and requires a high level of clinical skepticism. Furthermore, psychosis without delirium has infrequently been reported. We describe a 36-year-old female with PROP1 mutation who presented with psychosis and recovered completely with hormonal replacement therapy and antipsychotics. Due to the chronic nature of PROP1 gene mutation, proper diagnosis and prompt treatment must be instituted.

\section{Case presentation}

A 36-year-old dwarf female presented with complaints of delusion of reference, delusion of persecution, thought broadcasting and insomnia. One week before coming to the OPD, she called the emergency services and explained to police that her neighbors were reading her thoughts and that they were planning to kill her. The police officers investigated the complaint and later referred her to our hospital for consultation. She was casually dressed and maintained poor eye contact. Her speech was slow, but at a normal volume, lucid and coherent. Her affect was flat and her mood was irritable. She had paranoid ideations, ideas of reference and persecution, and evidence of thought broadcasting. There was a lack of insight. She denied having any suicidal or homicidal ideas, intent, or plan. She had no

() 2017 The authors
http://www.edmcasereports.com
Published by Bioscientifica Ltd Downloaded from Bioscientifica.com at 04/26/2023 10:51:30AM 
difficulty in interpretation and her judgment was intact. She appeared attentive and without any fluctuation of consciousness. She did not have any psychomotor agitation or memory disturbances that could suggest delirium. There was no history of fever, neck stiffness or focal neurological symptoms. Her abdominal, cardiovascular, respiratory and neurological examination was normal. There was no history of similar illness in the past.

On review of her medical record, it was found that she was diagnosed with congenital panhypopituitarism for which she took subcutaneous somatropin (rDNA origin) injection (Norditropin; growth hormone) for 18 years until she was 20 years old. She was prescribed sex hormone replacement for a few years and was prescribed $100 \mu \mathrm{g}$ thyroxine and $10 \mathrm{mg}$ prednisolone a few years ago. However her father revealed that she was noncompliant with her medications.

\section{Investigation}

Investigations were ordered (Table 1), and further treatment was started. Due to repetitive admission in different health-care facilities and 3 anterior pituitary hormones not being within laboratory parameters, we did a genetic consultation. After 6 weeks we received confirmation that she had PROP1 gene mutation. PROP1 mutation screening was done via PCR. Multiplex PCR i.e. MLPA detected a homozygous deletion of the PROP1 gene. The deletion was delimited to at least $7.7 \mathrm{~kb}$ upstream of PROP1 and more finely to $\sim 541-74$ bp downstream from PROP1. A total of six hormones were affected. TSH with milder elevation was found; it could be due to secondary hypothyroidism. Unfortunately, investigation for IGF-1 measurement was not done as we could not find any previous IGF-1 result.

\section{Treatment}

After endocrinology and psychiatry consultation she was prescribed $10 \mathrm{mg}$ prednisolone, $100 \mu \mathrm{g}$ thyroxine, $10 \mathrm{mg}$ aripiprazole and $2 \mathrm{mg}$ lorazepam. Within the next 5 days she reported significant improvement in symptoms. Her mood and affect were found to have improved, as did her delusions. She was discharged into the care of her family to preserve continued compliance with medications and she was scheduled for an endocrinology follow-up. Aripiprazole and lorazepam treatments were gradually stopped over the next 4 weeks. Eight months after the last visit, her father returned with complaints of a re-emergence of her psychotic symptoms similar to her previous experience but mild in severity and with significant paranoia. Her father told us that she had stopped taking her medications for the past month as she felt better without them. Subsequently, thyroxine and prednisolone were started. Within the next 2 weeks, she reported an improvement in her symptoms. She was managed by different physicians and hospitals for the past 20 years. After emergence of psychotic symptoms, she came to our hospital for further management and treatment. We are unsure why the sex hormone replacement therapy was not started earlier. But as per our treatment protocol, we treated her with antipsychotics, thyroid hormone and cortisol. Patient showed marked improvement within a month.

\section{Outcome and follow-up}

She has been on $75 \mu \mathrm{g}$ thyroxine and $10 \mathrm{mg}$ prednisolone for the past 15 months. She denies any complaints and is compliant with her medications. Based on the severity on the symptoms, we treated her with antipsychotics. But on

Table 1 Investigation report.

\begin{tabular}{|c|c|c|c|c|c|c|c|}
\hline & Normal range & $04 / 97$ & $02 / 98$ & $10 / 98$ & $08 / 08$ & $02 / 09$ & $01 / 15$ \\
\hline Chronological age (year) & & 16 & 17 & 17 & 27 & 28 & 34 \\
\hline Height (cm) & & 120 & & 127 & & & 130 \\
\hline Weight (kg) & & 28 & & 30.8 & & & 62 \\
\hline T3 & 75-200 ng/dL & 134.8 & 145.39 & 131.22 & & 178 & 40 \\
\hline T4 & $0.8-2.8 \mathrm{ng} / \mathrm{dL}$ & 3.2 & 2.30 & 2.65 & & 2.02 & 0.5 \\
\hline TSH & $0.3-5 \mathrm{U} / \mathrm{mL}$ & 1.04 & 0.88 & 3.56 & & 1.38 & 8.6 \\
\hline Estradiol & $10-60 \mathrm{pg} / \mathrm{mL}$ & & 78 & & & 92 & 80 \\
\hline $\mathrm{LH}$ & 2-18IU/mL & & 0.308 & & & 0.45 & 0.28 \\
\hline $\mathrm{FSH}$ & $0.3-10 \mathrm{IU} / \mathrm{mL}$ & & 0.828 & & & 0.96 & 0.75 \\
\hline Cortisol & $10-20 \mu \mathrm{g} / \mathrm{dL}$ & & & & 0.63 & 0.31 & 0.26 \\
\hline Prolactin & 10-209 ng/mL & 0.6 & 0.70 & & & 0.65 & 0.70 \\
\hline $\mathrm{Na}+$ & 135-145 mEq/L & 140 & 126 & 138 & 140 & 136 & 128 \\
\hline $\mathrm{K}+$ & $3.5-5 \mathrm{mEq} / \mathrm{L}$ & 4.6 & 3.7 & 4.6 & 3.8 & 4.2 & 3.4 \\
\hline Bone age (year) & & $6.8-7.4$ & $7.6-8.6$ & & & & \\
\hline
\end{tabular}


follow-up, her symptoms were mild and we treated her with hormonal therapy. We thereby postulated that the hormonal therapy was responsible for the resolution of psychotic symptoms.

\section{Discussion}

CPHD is a rare disorder characterized by impaired production of two or more anterior pituitary hormones. Possible etiology includes birth trauma, asphyxia or gene mutation controlling the differentiation of pituitary cells. It may occur sporadically or there may be familial occurrence including autosomal and $\mathrm{x}$-linked inheritance (4). Two of the main pituitary transcription factors are implicated in the onset of CPHD including POU1F1 and PROP1. The PROP1 gene is involved in the differentiation of pituitary cells secreting growth hormone, folliclestimulating hormone (FSH), prolactin (PRP), luteinizing hormone (LH) and thyroid-stimulating hormone (TSH) $(5,6)$. PROP1 gene mutations are responsible for the absence of the Pit1-dependent cell lineages and reduced numbers of gonadotropes resulting in deficiency of growth hormone, PRP, TSH, FSH and LH (7).

Her serum levels of thyroid hormone, FSH, LH and PRL were low, confirming the diagnosis of anterior lobe pituitary insufficiency. Despite the presence of impaired thyroid and adrenal gland, there were no signs or symptoms of hypothyroidism and hypocortisolism. We treated her with thyroxine and cortisol to prevent the lifethreatening features of adrenocortical insufficiency that may manifest in the event of severe psychological and physical conditions. We used antipsychotics for a short duration before being discontinued. She refused MRI evaluation, but her past MRI reports suggested that she had normal-sized pituitary gland.

Psychosis is a very rare manifestation of hypopituitarism in the absence of delirium. Leo and coworkers described it in their 2 case reports (8). In both of these case reports, patients presented with psychosis without delirium, and recovered with hormonal replacement and did not require antipsychotics. The development of psychosis due to hypopituitarism appeared pertinent to our patient, but she did not demonstrate the variation of consciousness, psychomotor agitation, delusions or impairments of memory linked to delirium. Cortisol deficiency or hypercortisolemia has subtle and nonspecific presentation, hence evaluation by an endocrinologist is recommended. Psychiatric symptoms may be the earliest manifestation and diagnosis can be missed. A physician should have high index of suspicion of this disease. Paradoxically, prolonged corticosteroid therapy can lead to psychotic symptoms which include insomnia, mood alterations, psychosis and hyperactivity (9). These symptoms have been reported in $5 \%$ of the patients treated with corticosteroid (10).

Patient presented with hyponatremia $\mathrm{CNa}^{+}$ $126 \mathrm{mEq} / \mathrm{L})$, which was managed successfully. Corticosteroid deficiency is an important factor leading to hyponatremia in a patient with hypopituitarism (11). Diederich et al. found that patients with hypopituitarism presenting with hyponatremia were admitted up to four times before the diagnosis of underlying hypopituitarism was made (11). Because of the varied presentation, the underlying diagnosis of hyponatremia secondary to hypopituitarism can be overlooked. Patients with PROP1 gene mutations may exhibit variation in physical phenotypes, hormonal phenotypes and pituitary morphology and this is often the reason for a delayed diagnosis $(7,12)$. It is necessary to emphasize the need for early etiologic classification and long-term follow-up in order to decrease the morbidity and mortality associated with this disease.

In summary, we would like to emphasize that in addition to GH, TSH, PRL and growth hormone deficiency, patients with mutations of PROP1 gene may present with psychosis. Possible mechanisms of psychosis in CPHD may be due to a combination of hypothyroidism, hypoglycemia and hypocortisolism resulting in complex metabolic and electrolyte changes in the central nervous system (13). Adequate medication compliance needs to be maintained to prevent the recurrence of the symptoms.

Declaration of interest

The authors declare that there is no conflict of interest that could be perceived as prejudicing the impartiality of the research reported.

\section{Funding}

This research did not receive any specific grant from any funding agency in the public, commercial or not-for-profit sector.

\section{Patient consent}

Informed consent has been obtained from the patient for the publications of the submitted article.

\section{Author contribution statement}

Jha $\mathrm{K} \mathrm{K}$ assembled the case history and investigations from hospital records, analyzed the data and wrote the paper. Chaudhary D P, Saluja $\mathrm{H}$ and Rijal $\mathrm{T}$ selected the case, assessed the patient data and critically reviewed the paper. 


\section{References}

1 Gupta SK, Agarwal MP, Gupta A, Mehra BB \& Dwivedi S 1995 Sheehan's syndrome presenting as psychosis. Tropical Doctor 2013 82-83. (doi:10.1177/004947559502500210)

2 Chang YC, Tsai JC \& Tseng FY 2006 Neuropsychiatric disturbances and hypopituitarism after traumatic brain injury in an elderly man. Journal of the Formosan Medical Association 2013 172-176. (doi:10.1016/S0929-6646(09)60341-7)

3 Hong SI, Cho DH, Kang HC, Chung DJ \& Chung MY 2006 Acute onset of steroid psychosis with very low dose of prednisolone in Sheehan's syndrome. Endocrine Journal 2013 255-258. (doi:10.1507/ endocrj.53.255)

4 Procter AM, Phillips JA III \& Cooper DN 1998 The molecular genetics of growth hormone deficiency. Journal of Human Genetics $\mathbf{1 0 3}$ 255-272. (doi:10.1007/s004390050815)

5 Ingraham HA, Chen R, Mangalam HJ, Elsholtz HP, Flynn SE, Lin CR, Simmons DM, Swanson L \& Rosenfeld MG 1988 A tissue specific transcription factor containing a homeodomain specifies a pituitary phenotype. Cell 50 519-529. (doi:10.1016/0092-8674(88)90038-4)

6 Andersen B, Pearse RV II, Jenne K, Sornson M, Lin SC, Bartke A \& Rosenfeld MG 1995 The Ames dwarf gene is required for Pit-1 gene activation. Developmental Biology 172 495-503. (doi:10.1006/ dbio.1995.8040)
7 Wu W, Cogan JD, Pfaffle RW, Dasen JS, Frisch H, O'Connell SM, Flynn SE, Brown MR, Mullis PE, Parks JS, et al. 1998 Mutations in PROP1 cause familial combined pituitary hormone deficiency. Nature Genetics 18 147-149. (doi:10.1038/ng0298-147)

8 Leo RJ, Burnett GJ \& Hassett MJ 1998 Psychosis associated with hypopituitarism. General Hospital Psychiatry 2013 248-254. (doi:10.1016/S0163-8343(98)00028-0)

9 Brown ES 2012 An epidemiological approach to 'steroid psychosis.' American Journal of Psychiatry 169 447-449. (doi:10.1176/appi. ajp.2012.12020181)

10 Buchman AL 2001 Side effects of corticosteroid therapy. Journal of Clinical Gastroenterology 33 289-294. (doi:10.1097/00004836200110000-00006)

11 Diederich S, Franzen N-F, Bähr V \& Oelkers W 2003 Severe hyponatraemia due to hypopituitarism with adrenal insuffiency: report on 28 cases. European Journal of Endocrinology 6 609-617. (doi:10.1530/eje.0.1480609)

12 Radovick S, Nations M, Du Y, Berg LA, Weintraub BD \& Wondisford FE 1992 A mutation in the POU homeodomain of Pit-1 responsible for combined pituitary hormone deficiency. Science $\mathbf{2 5 7}$ 1115-1118. (doi:10.1126/science.257.5073.1115)

13 Kate S, Dhanwal DK, Kumar S \& Bharti P 2013 Acute psychosis as a presentation of hypopituitarism. BMJ Case Reports $\mathbf{2 0 1 3}$ bcr2012008516. (doi:10.1136/bcr-2012-008516)

Received in final form 2 February 2017

Accepted 21 February 2017 